\title{
Importance of the Hydrogen Isocyanide Isomer in Modeling Hydrogen Cyanide Oxidation in Combustion
}

\author{
Peter Glarborg* ${ }^{* \dagger}$ and Paul Marshall ${ }^{*}$ \\ ${ }^{\dagger}$ DTU Chemical Engineering, Technical University of Denmark, 2800 Lyngby, Denmark \\ ${ }^{\ddagger}$ Department of Chemistry and Center for Advanced Scientific Computing and Modeling (CASCaM), University of North Texas, \\ 1155 Union Circle \#305070, Denton, Texas 76203-5017, United States
}

Supporting Information

ABSTRACT: Hydrogen isocyanide (HNC) has been proposed as an important intermediate in oxidation of hydrogen cyanide $(\mathrm{HCN})$ in combustion, but details of its chemistry are still in discussion. At higher temperatures, HCN and HNC equilibrate rapidly, and being more reactive than $\mathrm{HCN}, \mathrm{HNC}$ offers a fast alternative route of oxidation for cyanides. However, in previous modeling, it has been required to omit the HNC subset partly or fully in the reaction mechanisms to obtain satisfactory predictions. In the present work, we re-examine the chemistry of HNC and its role in combustion nitrogen chemistry. The HNC $+\mathrm{O}_{2}$ reaction is studied by $a b$ initio methods and is shown to have a high barrier. Consequently, the omission of this reaction in recent modeling studies is justified. With the present knowledge of the HNC chemistry, including an accurate value of the heat of formation for $\mathrm{HNC}$ and improved rate constants for $\mathrm{HNC}+\mathrm{O}_{2}$ and $\mathrm{HNC}+\mathrm{OH}$, it is possible to reconcile the modeling issues and provide a satisfactory prediction of a wide range of experimental results on $\mathrm{HCN}$ oxidation. In the burned gases of fuel-rich flames, $\mathrm{HCN}$ and the $\mathrm{CN}$ radical are partially equilibrated and the sequence $\mathrm{HCN} \stackrel{+\mathrm{M}}{\longrightarrow} \mathrm{HNC} \stackrel{+\mathrm{OH}}{\longrightarrow} \mathrm{HNCO}$ is the major consumption path for HCN. Under lean conditions, HNC is shown to be less important than indicated by the early work by Lin and co-workers, but it acts to accelerate $\mathrm{HCN}$ oxidation and promotes the formation of HNCO.

\section{INTRODUCTION}

In combustion processes, cyanides may be formed from devolatilization of fuels with organically bound nitrogen, from reaction of hydrocarbon radicals $\left(\mathrm{CH}\right.$ and $\mathrm{C}$ ) with $\mathrm{N}_{2}$ (the initiating step in prompt $\mathrm{NO}$ formation), from reaction of reactive nitrogen species, such as NO or amines, with hydrocarbon radicals, or from decomposition of hydrocarbon amines. $^{1-5}$ In sufficiently fuel-rich hydrocarbon flames, it appears that hydrogen cyanide $(\mathrm{HCN})$ is the dominant nitrogenous species leaving the primary reaction zone, regardless of the source of nitrogen, ${ }^{6-8}$ and it is considered the predominant cyanide species in combustion. The oxidation chemistry of $\mathrm{HCN}$ has been studied extensively over the years. Much of this work was reviewed recently by Dagaut et al. ${ }^{9}$

An unresolved issue in the oxidation chemistry of $\mathrm{HCN}$ is the role of its isomer, hydrogen isocyanide (HNC). As suggested initially by Lin et al., ${ }^{10}$ isomerization of $\mathrm{HCN}$ to $\mathrm{HNC}$, followed by oxidation of HNC, represents an alternative pathway for HCN oxidation. The reactivity of $\mathrm{HNC}$ is quite different from that of $\mathrm{HCN}$, and the presence of $\mathrm{HNC}$ in significant quantities may affect the oxidation behavior of $\mathrm{HCN}$. $\mathrm{HNC}$ is formed by isomerization of $\mathrm{HCN}$

$$
\mathrm{HCN}+\mathrm{M} \rightleftharpoons \mathrm{HNC}+\mathrm{M}
$$

or by a $\mathrm{H}$ atom exchange reaction of $\mathrm{HCN}$ with $\mathrm{H}$.

$$
\mathrm{HCN}+\mathrm{H} \rightleftharpoons \mathrm{HNC}+\mathrm{H}
$$

At high temperatures, these reactions lead to fast equilibration of $\mathrm{HNC}$ with $\mathrm{HCN}$. Once formed, $\mathrm{HNC}$ has been proposed to react rapidly with $\mathrm{OH}$ and $\mathrm{O}_{2}{ }^{11}$

$$
\begin{aligned}
& \mathrm{HNC}+\mathrm{OH} \rightleftharpoons \mathrm{HNCO}+\mathrm{H} \\
& \mathrm{HNC}+\mathrm{O}_{2} \rightleftharpoons \mathrm{HNCO}+\mathrm{O} \\
& \mathrm{HNC}+\mathrm{O}_{2} \rightleftharpoons \mathrm{NH}+\mathrm{CO}_{2}
\end{aligned}
$$

Because these steps are presumably much faster than the corresponding reactions of $\mathrm{HCN}$ with $\mathrm{OH}$ and $\mathrm{O}_{2}$, they serve to enhance the consumption rate of $\mathrm{HCN}$ and convert the cyanide pool to isocyanide species and amines. According to Dagaut et al., ${ }^{9}$ the impact of HNC on HCN consumption is most pronounced for the conditions in shock tubes and flow reactor systems, while it is less important in laminar premixed flames. However, inclusion of a kinetic subset for HNC with the accepted thermochemistry for this species and rate constants for HNC reactions drawn from the evaluation of Dean and Bozzelli ${ }^{11}$ leads to a considerable reduction in the accuracy of modeling predictions when compared to experimental data. ${ }^{9}$ To obtain acceptable modeling accuracy, Dagaut et al. ${ }^{9}$ omitted $\mathrm{HNC}+\mathrm{O}_{2}$ (reaction R16) from their reaction mechanism; otherwise, predicted ignition delays for $\mathrm{HCN}$ under shock-tube conditions were too low by an order of magnitude. Dagaut et al. concluded in their review that further work was needed to assess the kinetics of HNC reactions, in particular that of $\mathrm{HNC}+\mathrm{O}_{2}$. This suggestion was supported by

Special Issue: In Honor of Professor Brian Haynes on the Occasion of His 65th Birthday

Received: August 18, 2016

Revised: October 5, 2016

Published: October 5, 2016 
Table 1. Values Reported in the Literature for the Thermodynamic Properties of HNC (Heat of Formation of HNC and the Energy Difference between HNC and $\mathrm{HCN}$ )

\begin{tabular}{|c|c|c|c|}
\hline$\Delta H_{\mathrm{f}, 298}^{\circ}(\mathrm{HNC})-\Delta H_{\mathrm{f}, 298}^{\circ}(\mathrm{HCN})\left(\mathrm{kcal} \mathrm{mol}^{-1}\right)$ & $\Delta H_{\mathrm{f}, 298}^{\circ}(\mathrm{HNC})\left(\mathrm{kcal} \mathrm{mol}^{-1}\right)$ & method & reference \\
\hline 14.6 & $45.5^{a}$ & theory & 15 \\
\hline $15.0 \pm 2$ & $45.9 \pm 2^{a}$ & theory & 20 \\
\hline $10.3 \pm 1.1$ & $41.2 \pm 1.1^{a}$ & experimental & 22 \\
\hline$>17$ & $>47.9^{a}$ & experimental & 23 \\
\hline $14.8 \pm 2$ & $45.7 \pm 2^{a}$ & experimental & 24 \\
\hline $14.4 \pm 1$ & $45.3 \pm 1^{a}$ & theory & 32 \\
\hline 12.9 & $43.8^{a}$ & theory & 10 \\
\hline 14.7 & 45.6 & theory & 34 \\
\hline 15.2 & $46.1^{a}$ & theory & 35 \\
\hline 15.2 & $46.1^{a}$ & theory & 38 \\
\hline 13.8 & $44.7^{a}$ & theory & 76 \\
\hline 14.4 & $45.3 \pm 1^{a}$ & experimental & 42 \\
\hline $14.0 \pm 1^{b}$ & $44.9 \pm 1$ & experimental & 77 \\
\hline $18.8 \pm 2.9^{b}$ & $49.7 \pm 2.9$ & experimental & 45 \\
\hline 14.2 & $45.1^{a}$ & theory & 52 \\
\hline 16.3 & $47.2^{a}$ & experimental and theory & 61 \\
\hline 14.2 & $45.1^{a}$ & theory & 62 \\
\hline 15.07 & $45.95 \pm 0.09$ & theory and ATcT & 67 \\
\hline
\end{tabular}

${ }^{a}$ Estimated from $\Delta H_{\mathrm{f}, 298}^{\circ}(\mathrm{HNC})-\Delta H_{\mathrm{f}, 298}^{\circ}(\mathrm{HCN})$, assuming $\Delta H_{\mathrm{f}, 298}^{\circ}(\mathrm{HCN})=30.9 \mathrm{kcal} \mathrm{mol}^{-1} \cdot{ }^{67}{ }^{b}$ Estimated from $\Delta H_{\mathrm{f}, 298}^{\circ}(\mathrm{HNC})$, assuming $\Delta H_{\mathrm{f}, 298}^{\circ}(\mathrm{HCN})=30.9 \mathrm{kcal} \mathrm{mol}^{-1} \cdot{ }^{67}$

Table 2. Thermodynamic Properties of Selected Species in the Reaction Mechanism ${ }^{a}$

$\begin{array}{lrrrrrrrrr}\text { species } & H_{298} & S_{298} & C_{\mathrm{p}, 300} & C_{\mathrm{p}, 400} & C_{\mathrm{p}, 500} & C_{\mathrm{p}, 600} & C_{\mathrm{p}, 800} & C_{\mathrm{p}, 1000} & C_{\mathrm{p}, 1500} \\ \mathrm{HCN} & 31.02 & 48.23 & 8.59 & 9.36 & 9.97 & 10.48 & 11.31 & 12.01 & 13.20 \\ \mathrm{HNC} & 45.95 & 49.11 & 9.64 & 10.22 & 10.61 & 10.92 & 11.55 & 12.08 & 13.09 \\ \mathrm{CN} & 105.15 & 48.42 & 6.97 & 7.04 & 7.16 & 7.32 & 7.69 & 7.99 & 8.48\end{array}$

${ }^{a}$ Units are $\mathrm{kcal} \mathrm{mol}^{-1}$ for $\mathrm{H}$ and $\mathrm{cal} \mathrm{mol}^{-1} \mathrm{~K}^{-1}$ for $S$ and $C_{\mathrm{p}}$. Temperatures are in kelvin. Data are drawn from the thermodynamic database of Goos et al., ${ }^{78}$ except that the heat of formation of HNC was updated according to the work of Nguyen et al. ${ }^{67}$

Gimenez-Lopez et al. ${ }^{12}$ in a recent flow reactor study on HCN oxidation in $\mathrm{CO}_{2} / \mathrm{N}_{2}$ atmosphere, where they found inclusion of the $\mathrm{HNC}+\mathrm{O}_{2}$ reaction to lead to overprediction of the $\mathrm{HCN}$ consumption rate.

While the importance of HNC in combustion systems has attracted only modest interest, ${ }^{9-11,13,14}$ the properties of HNC have been studied extensively ${ }^{15-67}$ in part as a result of its small size, which allows for study at high levels of theory, and in part as a result of its potential importance in astrochemistry. The objective of the present work is to re-evaluate the HNC chemistry, with particular emphasis on $\mathrm{HNC}+\mathrm{O}_{2}$, which is studied by $a b$ initio methods, and assess the implications for modeling HCN oxidation in combustion.

\section{DETAILED KINETIC MODEL AND AB INITIO CALCULATIONS}

The cyanide subset of the chemical kinetic model was based on the work of Dagaut et al..$^{9}$ In the present study, the thermochemistry of $\mathrm{HNC}$ and rate constants for the reactions involved in forming or consuming HNC were re-evaluated. In addition, the hydrogen and amine chemistry subsets were updated on the basis of recent work. ${ }^{5,68-75}$ The full model is available as Supporting Information.

The thermodynamic properties of HNC are important, because they determine the $\mathrm{HNC} / \mathrm{HCN}$ ratio at high temperatures where the two isomers equilibrate rapidly. Table 1 summarizes the values reported in the literature for the heat of formation of HNC and the energy difference between $\mathrm{HNC}$ and $\mathrm{HCN}$. The early experimental determinations of the energy separation between the isomers range from $10.3^{22}$ to more than $17 \mathrm{kcal} \mathrm{mol}^{-1}$, ${ }^{23}$ but more recent work serves to reduce the uncertainty. Most theoretical predictions ${ }^{15,20,32,34,35,38,42,46,52,62,67}$ support a value for $\Delta H_{\mathrm{f}, 298}^{\circ}(\mathrm{HNC})-$ $\Delta H_{\mathrm{f}, 298}^{\circ}(\mathrm{HCN})$ of $14.2-15.3 \mathrm{kcal} \mathrm{mol}^{-1}$, in agreement with the experimental value of $14.8 \mathrm{kcal} \mathrm{mol}^{-1}$ from Pau and Hehre. ${ }^{24}$

The Pau and Hehre results were questioned by Wenthold ${ }^{45}$ based on revisions in the proton affinity scale in later years. From experimental work as well as a reinterpretation of the results of Pau and Hehre, Wenthold obtained a value for the heat of formation of $\mathrm{HNC}$ of $\Delta H_{\mathrm{f}, 298}^{\circ}(\mathrm{HNC})=49.7 \pm 2.9 \mathrm{kcal} \mathrm{mol}^{-1}$, corresponding to an energy difference between $\mathrm{HNC}$ and $\mathrm{HCN}$ of $18.8 \pm 2.9 \mathrm{kcal} \mathrm{mol}^{-1}$. A high value was also obtained recently by Barber et al. ${ }^{61}$ from a highlevel multireference configuration interaction study. They found an energy difference between $\mathrm{HNC}$ and $\mathrm{HCN}$ of $16.3 \mathrm{kcal} \mathrm{mol}^{-1}$, corresponding to a heat of formation for $\mathrm{HNC}$ of $47.2 \mathrm{kcal} \mathrm{mol}^{-1}$.

The high values of $\Delta H_{\mathrm{f}, 298}^{\circ}(\mathrm{HNC})$ determined by Wenthold ${ }^{45}$ and Barber et al. ${ }^{61}$ would diminish the importance of HNC in combustion modeling. However, they are called into question in the recent study by Nguyen et al., ${ }^{67}$ who investigated the $\mathrm{HCN} \rightarrow \mathrm{HNC} 0 \mathrm{~K}$ isomerization energy by combining state-of-the-art electronic structure methods with the active thermochemical tables (ATcT) approach. They found the energy difference between $\mathrm{HCN}$ and $\mathrm{HNC}$ at $298 \mathrm{~K}$ to be $15.1 \mathrm{kcal} \mathrm{mol}^{-1}$. This is substantially lower than the values of Barber et al. and Wenthold (by 1.2 and $3.7 \mathrm{kcal} \mathrm{mol}^{-1}$, respectively). Nguyen et al. concluded that the value from Barber et al. was likely to have a much larger uncertainty than originally stated. The analysis from Nguyen et al. indicates that the heat of formation of HNC at 298 $\mathrm{K}$ is $45.95 \pm 0.09 \mathrm{kcal} \mathrm{mol}^{-1}$; we have adopted this value in the present work. An energy separation between HNC and HCN of $15.1 \mathrm{kcal}$ $\mathrm{mol}^{-1}$ is $2.2 \mathrm{kcal} \mathrm{mol}^{-1}$ higher than that used in the early study by Lin et al. $^{10}$ and adopted by Dean and Bozzelli ${ }^{11}$ and recently by 
Table 3. Selected Reactions in the HCN Subset ${ }^{a}$

\begin{tabular}{|c|c|c|c|c|c|}
\hline & & $A$ & $\beta$ & $E_{\mathrm{a}}$ & source \\
\hline \multirow[t]{2}{*}{1} & $\mathrm{HCN}+\mathrm{M} \rightleftharpoons \mathrm{CN}+\mathrm{H}+\mathrm{M}^{b}$ & $3.4 \times 10^{35}$ & -5.130 & 133000 & 81 \\
\hline & $\mathrm{HCN}+\mathrm{N}_{2} \rightleftharpoons \mathrm{CN}+\mathrm{H}+\mathrm{N}_{2}$ & $3.6 \times 10^{26}$ & -2.600 & 124890 & \\
\hline 2 & $\mathrm{HCN}+\mathrm{M} \rightleftharpoons \mathrm{HNC}+\mathrm{M}^{c}$ & $1.6 \times 10^{26}$ & -3.230 & 51840 & $11^{d}$ \\
\hline 3 & $\mathrm{CN}+\mathrm{H}_{2} \rightleftharpoons \mathrm{HCN}+\mathrm{H}$ & $1.1 \times 10^{5}$ & 2.600 & 51908 & 82 \\
\hline 4 & $\mathrm{HCN}+\mathrm{O} \rightleftharpoons \mathrm{NCO}+\mathrm{H}$ & $1.4 \times 10^{4}$ & 2.640 & 4980 & 1 \\
\hline 5 & $\mathrm{HCN}+\mathrm{O} \rightleftharpoons \mathrm{NH}+\mathrm{CO}$ & $3.5 \times 10^{3}$ & 2.640 & 4980 & 1 \\
\hline 7 & $\mathrm{HCN}+\mathrm{OH} \rightleftharpoons \mathrm{CN}+\mathrm{H}_{2} \mathrm{O}$ & $3.9 \times 10^{6}$ & 1.830 & 10300 & 83 \\
\hline 8 & $\mathrm{HCN}+\mathrm{OH} \rightleftharpoons \mathrm{HOCN}+\mathrm{H}$ & $5.9 \times 10^{4}$ & 2.430 & 12500 & 84 \\
\hline 9 & $\mathrm{HCN}+\mathrm{OH} \rightleftharpoons \mathrm{HNCO}+\mathrm{H}$ & $2.0 \times 10^{-3}$ & 4.000 & 1000 & 84 \\
\hline 10 & $\mathrm{HCN}+\mathrm{OH} \rightleftharpoons \mathrm{NH}_{2}+\mathrm{CO}$ & $7.8 \times 10^{-4}$ & 4.000 & 4000 & 84 \\
\hline 11 & $\mathrm{HCN}+\mathrm{O}_{2} \rightleftharpoons \mathrm{CN}+\mathrm{HO}_{2}$ & $3.0 \times 10^{13}$ & 0.000 & 75100 & 9 est \\
\hline 12 & $\mathrm{HNC}+\mathrm{H} \rightleftharpoons \mathrm{HCN}+\mathrm{H}$ & $7.8 \times 10^{13}$ & 0.000 & 3600 & 85 \\
\hline 13 & $\mathrm{HNC}+\mathrm{O} \rightleftharpoons \mathrm{NH}+\mathrm{CO}$ & $4.6 \times 10^{12}$ & 0.000 & 2200 & 11 \\
\hline 15 & $\mathrm{HNC}+\mathrm{OH} \rightleftharpoons \mathrm{CN}+\mathrm{H}_{2} \mathrm{O}$ & $3.0 \times 10^{2}$ & 3.160 & 10600 & pw \\
\hline 16 & $\mathrm{HNC}+\mathrm{O}_{2} \rightarrow$ products & & slow & & $\mathrm{pw}^{f}$ \\
\hline
\end{tabular}

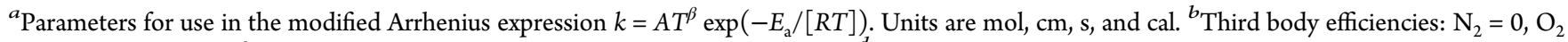
$=1.5$, and $\mathrm{H}_{2} \mathrm{O}=10 .{ }^{c}$ Third body efficiencies: $\mathrm{Ar}=0.7, \mathrm{H}_{2} \mathrm{O}=7$, and $\mathrm{CO}_{2}=2 .{ }^{d}$ The activation energy was modified according to the updated heat of formation of $\mathrm{HNC}$. ${ }^{e}$ Arrhenius expression fitted from data in the reference. ${ }^{f}$ The $\mathrm{HNC}+\mathrm{O}_{2}$ reaction has a calculated barrier of $44 \mathrm{kcal}^{\mathrm{mol}}{ }^{-1}$ and was not included in the modeling.

Lamoureux et al., ${ }^{14}$ and $0.3 \mathrm{kcal} \mathrm{mol}^{-1}$ higher than the recommendation of Dagaut et al. ${ }^{9}$

Table 2 lists thermodynamic properties for $\mathrm{HNC}, \mathrm{HCN}$, and cyanide $(\mathrm{CN})$. The thermodynamic properties in the present work were generally adopted from the ideal gas thermochemical database by Goos et al., ${ }^{78}$ with properties obtained using the ATcT approach. ${ }^{79,80}$

Table 3 lists key reactions of HCN and HNC from the chemical kinetic model. There are no reported experimental studies of HNC reactions, and rate constants have been obtained from theory. However, from the available theoretical studies, it is obvious that the reactivity of $\mathrm{HNC}$ is quite different from that of $\mathrm{HCN}$. HNC can be formed by isomerization of $\mathrm{HCN}$

$$
\mathrm{HCN}+\mathrm{M} \rightleftharpoons \mathrm{HNC}+\mathrm{M}
$$

or by reaction of $\mathrm{HCN}$ with $\mathrm{H}$.

$$
\mathrm{HCN}+\mathrm{H} \rightleftharpoons \mathrm{HNC}+\mathrm{H}
$$

The isomerization step has been studied extensively by theory. ${ }^{10,11,32,34,35,38,42,49,52,53,64}$ Estimates of the barrier for the isomerization range from 44.7 to $48.2 \mathrm{kcal}$ $\mathrm{mol}^{-1} \cdot{ }^{10,11,32,34,35,38,42}$ With a barrier of this magnitude, isomerization (reaction R2) is much faster than thermal dissociation of $\mathrm{HCN}$ (reaction R1) and $\mathrm{HCN}$ will isomerize fairly easily to HNC at medium to high temperatures. Following Dagaut et al., ${ }^{9}$ we have adopted the rate constant for reaction R2 from the evaluation of Dean and Bozzelli ${ }^{11}$ but modified the activation energy to reflect the larger energy separation between HCN and HNC. Also, reaction R12b has been studied theoretically; ${ }^{85,87}$ we have included this step in the exothermic direction, $\mathrm{HNC}+\mathrm{H} \rightleftharpoons \mathrm{HCN}+\mathrm{H}$ (R12), with a rate constant calculated by Sumathi and Nguyen. ${ }^{85}$

The most important consumption reaction of $\mathrm{HNC}$ is presumably $\mathrm{HNC}+\mathrm{OH}$.

$$
\mathrm{HNC}+\mathrm{OH} \rightleftharpoons \mathrm{HNCO}+\mathrm{H}
$$

Figure 1 shows an Arrhenius plot for the reaction. In their early evaluation, Lin et al. ${ }^{10}$ calculated an activation energy for reaction R14 of $3.7 \mathrm{kcal} \mathrm{mol}^{-1}$. Recently, the reaction was studied at a high level of theory by Bunkan et al. ${ }^{86}$ for the 250$350 \mathrm{~K}$ range. They predict the rate constant to have a slight negative temperature dependence, at least at low temperatures.

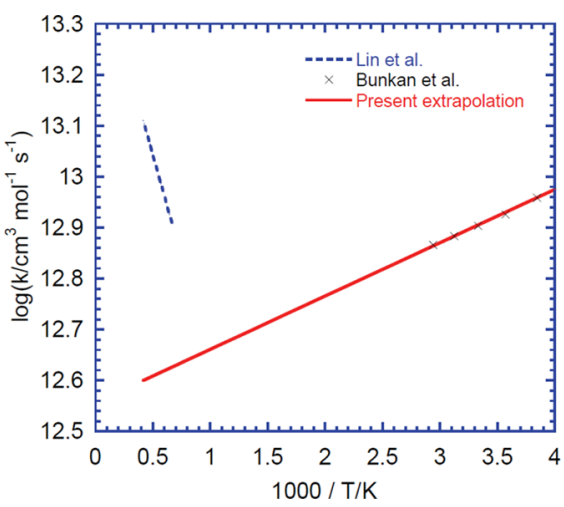

Figure 1. Arrhenius plot for the reaction $\mathrm{HNC}+\mathrm{OH} \rightleftharpoons \mathrm{HNCO}+\mathrm{H}$. The symbols denote high level theory data from Bunkan et al., ${ }^{86}$ while the dashed line denotes the rate constant calculated by Lin et al. ${ }^{10}$ The solid line is our extrapolation of the data of Bunkan et al. to relevant temperatures.

Their reaction path shows a pre-reaction complex followed by a transition state (TS), whose energy is $\sim 1.1 \mathrm{kcal} \mathrm{mol}^{-1}$ below that of the reactants. Their Rice-Ramsperger-Kassel-Marcus (RRKM) kinetic analysis should correctly allow for the lack of population of energy levels of the TS below the reactants at modest pressures. On the basis of a recomputation of the unpublished $\operatorname{CCSD}(\mathrm{T})$ frequencies of the TS, we have made a preliminary assessment of the high pressure limit via transition state theory. This calculation indicates that $k_{14, \infty}$ may reach a minimum and then increase at higher temperatures. However, more work is required to calculate accurately the effect of the temperature and pressure on this reaction. In the current work, we have extrapolated directly the results from Bunkan et al. to higher temperatures with a small negative activation energy (Figure 1) fitted to the published $k_{14}$ values.

For the possible other product channel

$$
\mathrm{HNC}+\mathrm{OH} \rightleftharpoons \mathrm{CN}+\mathrm{H}_{2} \mathrm{O}
$$

Bunkan et al. deduced a barrier of more than $16 \mathrm{kcal} \mathrm{mol}^{-1}$, which makes that channel too slow to compete under atmospheric 
conditions. A combination of their barrier with M06-2X/6-311+G(3df,2p) vibrational frequencies and geometry for the TS leads to a predicted rate constant of $3.0 \times 10^{2} T^{3.16} \exp (-5330 / T) \mathrm{cm}^{3} \mathrm{~mol}^{-1} \mathrm{~s}^{-1}$ over $600-3000 \mathrm{~K}$. Tunneling makes a major contribution; thus, there is considerable uncertainty in this expression, perhaps an order of magnitude at the lower end of the temperature range.

For the reaction of $\mathrm{HNC}$ with $\mathrm{O}$

$$
\mathrm{HNC}+\mathrm{O} \rightleftharpoons \mathrm{NH}+\mathrm{CO}
$$

we adopt the rate constant proposed by Lin et al. ${ }^{10}$ from a combined experimental and theoretical study. Unfortunately, the experimental results referred to by Lin et al. were never published, and more work on this step is desirable.

Dean and Bozzelli suggested that oxygen could readily add to HNC and that subsequent isomerization or dissociation steps would lead to $\mathrm{HNCO}+\mathrm{O}$ and $\mathrm{NH}+\mathrm{CO}_{2} \cdot{ }^{11}$

$$
\begin{aligned}
& \mathrm{HNC}+\mathrm{O}_{2} \rightleftharpoons \mathrm{HNCO}+\mathrm{O} \\
& \mathrm{HNC}+\mathrm{O}_{2} \rightleftharpoons \mathrm{NH}+\mathrm{CO}_{2}
\end{aligned}
$$

They computed low barriers for both channels and obtained rate constants of $k_{16 \mathrm{a}}=1.5 \times 10^{12} \mathrm{~T}^{0.01} \exp (-2068 / \mathrm{T}) \mathrm{cm}^{3}$ $\mathrm{mol}^{-1} \mathrm{~s}^{-1}$ and $k_{16 \mathrm{~b}}=1.6 \times 10^{19} \mathrm{~T}^{-2.25} \exp (-896 / \mathrm{T}) \mathrm{cm}^{3} \mathrm{~mol}^{-1}$ $\mathrm{s}^{-1}$. However, Dagaut et al. ${ }^{9}$ found it necessary to omit the $\mathrm{HNC}+\mathrm{O}_{2}$ reactions in their modeling study to obtain consistency with experimental results. More recently, GimenezLopez et al. ${ }^{12}$ and Lamoreux et al. ${ }^{14}$ also disregarded HNC + $\mathrm{O}_{2}$ in their reaction mechanisms. This prompted us to characterize the reaction by $a b$ initio methods.

We find that a triplet $\mathrm{HNCOO}$ adduct lies ca. $42 \mathrm{kcal} \mathrm{mol}^{-1}$ above $\mathrm{HNC}+\mathrm{O}_{2}$ at the CBS-QB3 level of theory, and the barrier to forming this adduct (including zero-point energy) is even higher, at about 44 $\mathrm{kcal} \mathrm{mol}^{-1}$, which is confirmed by $\operatorname{CCSD}(\mathrm{T}) / \mathrm{cc}-\mathrm{pVTZ}$ calculations. ${ }^{88,89}$ The high energy barrier makes the reaction insignificant under most conditions of interest. Singlet HNCOO is even less stable.

The reaction of $\mathrm{HCN}$ with $\mathrm{OH}$ is of particular interest in this work, because it competes directly with $\mathrm{HNC}+\mathrm{OH}$ (reaction R14). It is a complicated process, involving multiple potential wells and multiple product channels.

$$
\begin{aligned}
& \mathrm{HCN}+\mathrm{OH} \rightleftharpoons \mathrm{CN}+\mathrm{H}_{2} \mathrm{O} \\
& \mathrm{HCN}+\mathrm{OH} \rightleftharpoons \mathrm{HOCN}+\mathrm{H} \\
& \mathrm{HCN}+\mathrm{OH} \rightleftharpoons \mathrm{HNCO}+\mathrm{H} \\
& \mathrm{HCN}+\mathrm{OH} \rightleftharpoons \mathrm{NH}_{2}+\mathrm{CO}
\end{aligned}
$$

The rate constant for the $\mathrm{H}$-abstraction channel to form $\mathrm{CN}+\mathrm{H}_{2} \mathrm{O}$ (reaction R7) has been measured directly in both the forward and reverse directions. Figure 2 shows an Arrhenius plot for this step. Wooldridge et al..$^{83}$ determined $k_{7}$ from $\mathrm{CN}$ and $\mathrm{OH}$ time histories in shock-tube experiments. The results shown from Jacobs et al. ${ }^{90}$ were obtained for the reverse reaction and have been converted using the present thermodynamic properties for the involved species. The two data sets are in very good agreement, indicating that the rate constant for this reaction is known quite accurately. The experiments of Wooldridge et al. are analyzed further below.

For the other product channels of $\mathrm{HCN}+\mathrm{OH}$ (reactions R8-R10), rate constants are drawn from BAC-MP4 calculations by Miller and Melius. ${ }^{84}$ There are no experimental data for these product channels, and more work is desirable to support the rate constants. At most conditions, the $\mathrm{H}$-abstraction reaction (reaction $\mathrm{R} 7$ ) dominates, but at very low temperatures, the formation of $\mathrm{HNCO}+\mathrm{H}$ (reaction R9) is competitive, while at temperatures above $2000 \mathrm{~K}, \mathrm{HOCN}+\mathrm{H}$ (reaction R8) becomes the fastest channel.

\section{RESULTS AND DISCUSSION}

This section aims to clarify the role of HNC in oxidation of $\mathrm{HCN}$ at medium to high temperatures relevant for combustion. $\mathrm{HCN}$ is presumably the most important precursor of $\mathrm{HNC}$ in

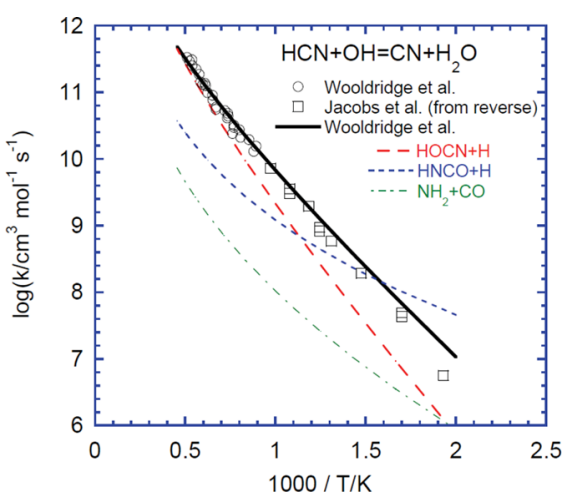

Figure 2. Arrhenius plot for the reaction $\mathrm{HCN}+\mathrm{OH} \rightleftharpoons \mathrm{CN}+\mathrm{H}_{2} \mathrm{O}$ (R7). The symbols denote experimental results from Wooldridge et al. ${ }^{83}$ and from Jacobs et al. ${ }^{90}$ (from measurements of $\mathrm{CN}+\mathrm{H}_{2} \mathrm{O}$, reversed through the equilibrium constant), while the solid line shows the constant recommended by Wooldridge et al. Also shown (dashed lines) are rate constants for the secondary channels to $\mathrm{HOCN}+\mathrm{H}$ (reaction $\mathrm{R} 8$ ), $\mathrm{HNCO}+\mathrm{H}$ (reaction $\mathrm{R} 9$ ), and $\mathrm{NH}_{2}+\mathrm{CO}$ (reaction R10), drawn from BAC-MP4 calculations by Miller and Melius. ${ }^{84}$

combustion, and the expected role of HNC is to accelerate the $\mathrm{HCN}$ consumption, converting it to isocyanides and amines.

Haynes ${ }^{8}$ investigated the decay of $\mathrm{HCN}$ in the burnt gases of a number of fuel-rich, atmospheric pressure hydrocarbon flames. Independent of the type of nitrogen additive (ammonia or pyridine), it was converted to $\mathrm{HCN}$ in the reaction zone of the flame, with smaller amounts of NO. In the post-flame zone, $\mathrm{HCN}$ was slowly converted to $\mathrm{NH}_{3}$. Haynes found the decay mechanism for $\mathrm{HCN}$ at temperatures below $2300 \mathrm{~K}$ to be firstorder in $\mathrm{OH}$, and he assumed it to be

$$
\mathrm{HCN}+\mathrm{OH} \rightarrow(\mathrm{HOCN})+\mathrm{H}
$$

or a kinetically equivalent process, with the (HOCN) isomer eventually converted to $\mathrm{NH}_{3}$.

Figure 3 compares measurements by Haynes for a rich ethylene flame doped with ammonia to modeling predictions. The temperature of the burnt gases was $2000 \mathrm{~K}$. In the modeling predictions, only the post-flame zone was considered.

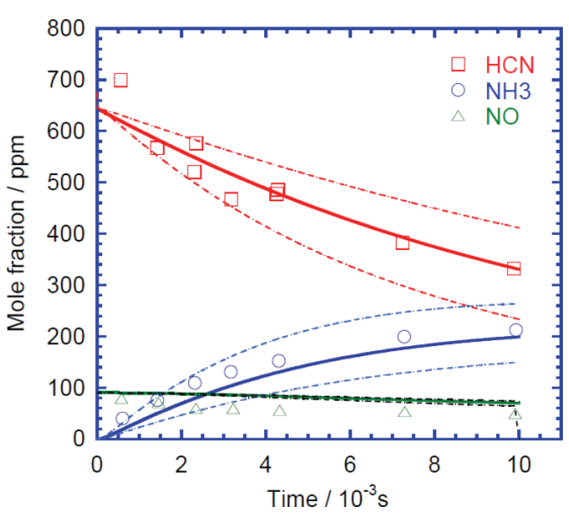

Figure 3. Comparison between experimental data $^{8}$ and modeling predictions for $\mathrm{HCN}$ oxidation in the post-flame region of an atmospheric pressure, premixed, fuel-rich ethylene-air flame doped with $680 \mathrm{ppm}$ of ammonia. Fuel-air equivalence ratio $\phi=1.66$, and temperature $=2000 \mathrm{~K}$. Symbols denote experimental data, while lines denote model predictions. Solid lines denote predictions with the present model, while dashed lines show the effect of varying the rate constant $k_{14}$ for $\mathrm{HNC}+\mathrm{OH}$ by a factor of 2 . 
It was assumed that both acetylene and oxygen were depleted in the reaction zone, resulting in an equilibrium mixture of $\mathrm{CO}$, $\mathrm{H}_{2}, \mathrm{CO}_{2}$, and $\mathrm{H}_{2} \mathrm{O}$ entering the post-flame zone. In the calculations, the equilibrium composition at $2000 \mathrm{~K}$, together with the measured concentrations of $\mathrm{HCN}, \mathrm{NH}_{3}$, and $\mathrm{NO}$, was used as the inlet composition. The modeling predictions (solid lines) are in good agreement with the measurements for $\mathrm{HCN}$, $\mathrm{NH}_{3}$, and NO. Analysis of the present calculations indicates that $\mathrm{HCN}$ is consumed through a two-step sequence.

$$
\begin{aligned}
& \mathrm{HCN}+\mathrm{M} \rightleftharpoons \mathrm{HNC}+\mathrm{M} \\
& \mathrm{HNC}+\mathrm{OH} \rightleftharpoons \mathrm{HNCO}+\mathrm{H}
\end{aligned}
$$

This sequence is kinetically equivalent to the reaction proposed by Haynes. Under the conditions in the flame, HCN equilibrates rapidly with $\mathrm{HNC}$. Atomic hydrogen and to a lesser extent $\mathrm{OH}$ are the dominant radicals in the flame, but they consume little $\mathrm{HCN}$ because the reactions $\mathrm{HCN}+\mathrm{H} \rightleftharpoons$ $\mathrm{CN}+\mathrm{H}_{2}(\mathrm{R} 3 \mathrm{~b})$ and $\mathrm{HCN}+\mathrm{OH} \rightleftharpoons \mathrm{CN}+\mathrm{H}_{2} \mathrm{O}(\mathrm{R} 7)$ are both rapidly equilibrated. This makes the conditions favorable to study the reactions of $\mathrm{HNC}$, in particular $\mathrm{HNC}+\mathrm{OH}$ (reaction $\mathrm{R} 14$ ), even though other product channels for $\mathrm{HCN}+\mathrm{OH}$, in particular reaction $\mathrm{R} 8$, are also active. The HNCO formed in reaction $\mathrm{R} 14$ feeds rapidly into the amine pool, eventually forming $\mathrm{NH}_{3}$.

$$
\begin{aligned}
& \mathrm{HNCO}+\mathrm{H} \rightleftharpoons \mathrm{NH}_{2}+\mathrm{CO} \\
& \mathrm{NH}_{2}+\mathrm{H}_{2} \rightleftharpoons \mathrm{NH}_{3}+\mathrm{H}
\end{aligned}
$$

A smaller fraction of $\mathrm{NH}_{2}$ is converted to $\mathrm{NH}$ and $\mathrm{N}$ through the sequence $\mathrm{NH}_{2} \stackrel{+\mathrm{H}}{\longrightarrow} \mathrm{NH} \stackrel{+\mathrm{H}}{\longrightarrow} \mathrm{N}$. The $\mathrm{NH}$ and $\mathrm{N}$ radicals may be oxidized to $\mathrm{NO}$ by reaction with $\mathrm{OH}$ or react with $\mathrm{NO}$ to form $\mathrm{N}_{2} \mathrm{O}$ or $\mathrm{N}_{2}$. This competition results overall in a small decrease in the NO concentration.

In Figure 3, dashed lines show predictions with the rate constant for HNC $+\mathrm{OH}$ (reaction R14) varied by a factor of 2 . The results show that the predicted $\mathrm{HCN}$ and $\mathrm{NH}_{3}$ profiles are quite sensitive to the value of $k_{14}$. This is confirmed by Figure 4,

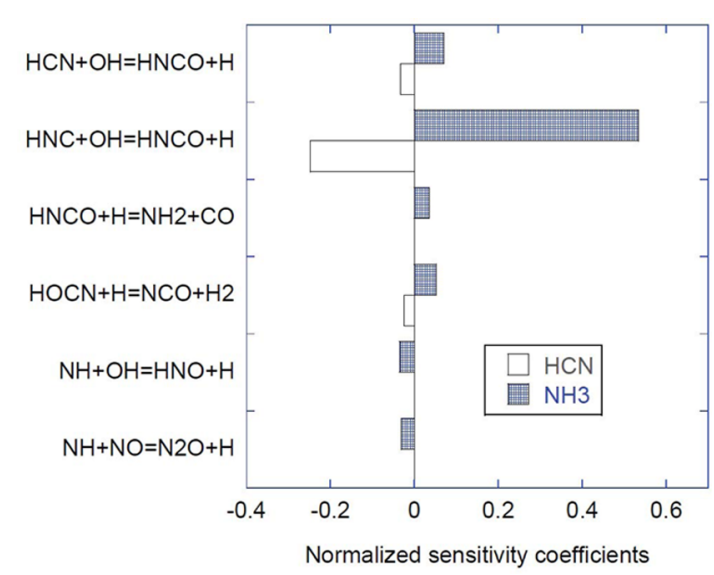

Figure 4. First-order sensitivity coefficients for $\mathrm{HCN}$ and $\mathrm{NH}_{3}$ for the conditions of the flame in Figure 3.

which shows the results of a sensitivity analysis for $\mathrm{HCN}$ and $\mathrm{NH}_{3}$ for the conditions of Figure 3. For HCN, the rate constant for reaction $\mathrm{R} 14$ has by far the largest sensitivity coefficient. Also, the predicted $\mathrm{NH}_{3}$ concentration is sensitive mostly to this step. The good agreement obtained in modeling for both of these species supports the accuracy of $k_{14}$ at this temperature.
The $\mathrm{OH}$ radical maintains a partial equilibrium in the postflame region, and modeling predictions are not sensitive to chain-branching or terminating steps.

For high-temperature conditions in a shock tube, the isomerization of $\mathrm{HCN}$ to $\mathrm{HNC}$ is sufficiently rapid to occur at the same microsecond time scale as the observed chemistry ${ }^{11}$ and predicted induction times for $\mathrm{HCN} / \mathrm{O}_{2}$ mixtures are quite sensitive to the HNC subset. ${ }^{9}$ Higashihara et al. ${ }^{91}$ studied the oxidation of $\mathrm{HCN}$ by $\mathrm{O}_{2}$ in a shock tube over the temperature range of $1450-2600 \mathrm{~K}$ and pressures of $0.75-2.0 \mathrm{~atm}$. They measured the ultraviolet (UV) signal from electronically excited $\mathrm{OH}$ and defined the induction time $\tau_{\mathrm{OH}^{*}}$ as the time where the UV emission started to increase rapidly. $\mathrm{OH}^{*}$ was assumed to be formed largely from recombination of $\mathrm{O}$ and $\mathrm{H}$ radicals. For the $\mathrm{HCN} / \mathrm{O}_{2}$ system, the $\mathrm{OH}^{*}$ induction time from a least squares analysis could be represented as $\tau_{\mathrm{OH}^{*}}=10^{-13.42}$ $\exp (-12200 / \mathrm{T})[\mathrm{HCN}]^{-0.44}\left[\mathrm{O}_{2}\right]^{-0.17}[\mathrm{Ar}]^{-0.52} \mathrm{~s}$.

In Figure 5, data estimated from this empirical expression are compared to predictions using the chemical kinetic model. In

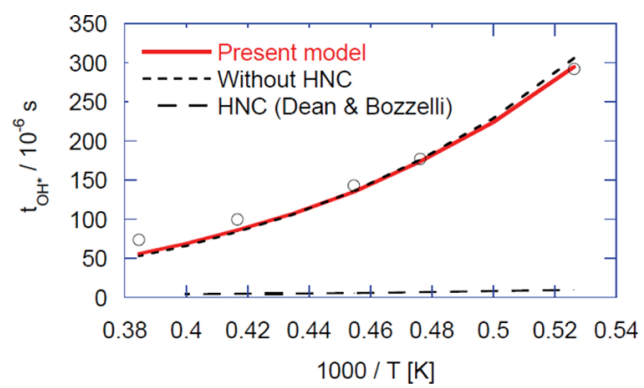

Figure 5. Comparison between measured ${ }^{91}$ and predicted induction times as a function of the temperature for oxidation of $\mathrm{HCN}(1 \%)$ by $\mathrm{O}_{2}(1 \%)$ in argon in a shock tube. The experimental data are derived from the least squares analysis expression by Higashihara et al., assuming $P=1.0 \mathrm{~atm}$. In the calculations, the induction time is taken as the time to reach $25 \%$ of the peak concentration for O. Experimental data are shown as symbols, while modeling predictions are shown as lines.

this figure as well as in the following, modeling predictions are shown for three different mechanisms: (1) full present mechanism, (2) present mechanism excluding the HNC subset, and (3) present mechanism with $\Delta H_{\mathrm{f}, 298}^{\circ}$ (HNC) $\Delta H_{\mathrm{f}, 298}^{\circ}(\mathrm{HCN})=12.9 \mathrm{kcal} \mathrm{mol}^{-110,11,14}$ and rate constants from Dean and Bozzelli, ${ }^{11}$ including the $\mathrm{HNC}+\mathrm{O}_{2}$ reaction.

In the modeling of the data in Figure 5, the $\mathrm{OH}^{*}$ induction time is defined as the time to reach $25 \%$ of the peak concentration of $\mathrm{O}$. Predictions with the present model with (solid line) and without (short dashed line) the HNC subset are both in good agreement with the measured induction times. The similarity between predictions with and without HNC indicates that this species, with the present chemistry, plays only a small role under these conditions. However, if the HNC subset is replaced by that recommended by Dean and Bozzelli, ${ }^{11}$ the predicted induction time is lowered by more than a factor of 10, in conflict with the experimental observations. The too low value for the energy separation between HNC and $\mathrm{HCN}$ contributes to the discrepancy, because it leads to overprediction of the HNC concentration. However, most of the difference is caused by the fast rate constants for $\mathrm{HNC}+\mathrm{O}_{2}$ estimated by Dean and Bozzelli.

Wooldridge et al. ${ }^{83}$ measured $\mathrm{CN}$ and $\mathrm{OH}$ time histories in incident and reflected shock waves using dilute mixtures of 
$\mathrm{HCN}$ and nitric acid $\left(\mathrm{HNO}_{3}\right)$ in argon. The thermal decomposition of $\mathrm{HNO}_{3}$ yielded $\mathrm{OH}$ upon shock heating, and $\mathrm{OH}$ subsequently reacted predominantly with $\mathrm{HCN}$. As discussed above, they used the data to deduce a rate constant for the reaction $\mathrm{HCN}+\mathrm{OH} \rightleftharpoons \mathrm{CN}+\mathrm{H}_{2} \mathrm{O}$ (R7). Their simultaneous measurements of $\mathrm{CN}$ and $\mathrm{OH}$ yielded values of $k_{7}$ in good agreement, putting severe limitations on the importance of the HNC isomer. Wooldridge et al. concluded that they had to omit reactions of HNC to obtain a satisfactory agreement between their observed concentration profiles and modeling results. A further constraint on $\mathrm{HNC}+\mathrm{OH}$ is the excellent consistency between the two data sets from Wooldridge et al. and Jacobs et al..$^{90}$ (Figure 2). Apparently, $\mathrm{HNC}+\mathrm{OH}$ cannot have had a significant impact on the $\mathrm{OH}$ concentration profile in the experiments of Wooldridge et al.

Figure 6 shows a comparison between experimental results obtained at $1492 \mathrm{~K}$ and modeling predictions to the present

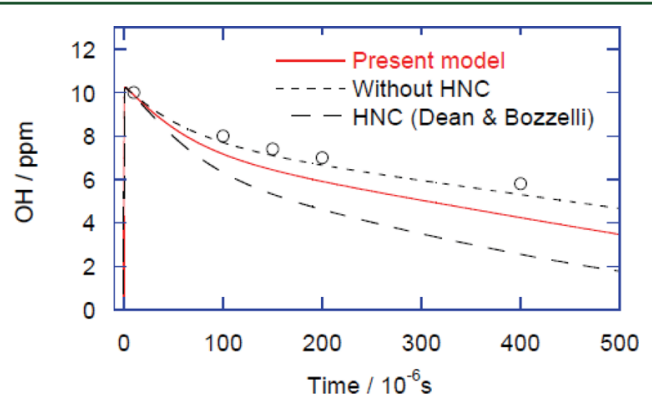

Figure 6. Comparison between measured ${ }^{83}$ and predicted $\mathrm{OH}$ absorption traces from the reflected shock pyrolysis of $10.3 \mathrm{ppm}$ of $\mathrm{HNO}_{3}$ and $0.34 \% \mathrm{HCN}$ in argon for $T=1492 \mathrm{~K}$ and $P=1.01 \mathrm{~atm}$. Experimental data are shown as symbols, while modeling predictions are shown as lines.

reaction mechanism. For these conditions, Wooldridge et al. reported only the $\mathrm{OH}$ concentration profile; at higher temperatures, where concentrations were reported for both $\mathrm{OH}$ and $\mathrm{CN}$, predictions are less sensitive to reactions of $\mathrm{HNC}$ because $\mathrm{HCN}+\mathrm{OH}$ becomes more competitive. As expected, the model (solid line) is seen to overestimate the $\mathrm{OH}$ consumption rate. The discrepancy, which is due to $\mathrm{OH}$ consumption by $\mathrm{HNC}+\mathrm{OH}$ (reaction R14), can be removed by taking out $\mathrm{HNC}$ from the reaction mechanism (short dashed line), as proposed by Wooldridge et al. However, we find the level of agreement to be satisfactory because it is within the $30 \%$ overall uncertainty attributed to $k_{7}$ by Wooldridge et al. as a result of uncertainties in side reactions. As expected, predictions with the Dean and Bozzelli HNC subset (long dashed line) show a larger deviation, partly as a result of the difference in thermochemistry and partly as a result of a faster rate constant for $\mathrm{HNC}+\mathrm{OH}$.

Figure 7 compares flow reactor results from Glarborg and Miller $^{13}$ on lean $\mathrm{HCN}$ oxidation to modeling predictions. The experiments were conducted at $900-1400 \mathrm{~K}$ and atmospheric pressure with a dilute mixture of $\mathrm{HCN}, \mathrm{O}_{2}$, and $\mathrm{H}_{2} \mathrm{O}$ in $\mathrm{N}_{2}$, and the product composition at the reactor outlet was measured. The calculations show a considerable impact of the choice of HNC subset. The preferred model provides a good agreement with the measured profiles of $\mathrm{HCN}, \mathrm{HNCO}$, and $\mathrm{NO}$, while omission of the HNC subset leads to delayed onset of the reaction. The Dean and Bozzelli HNC subset leads to premature ignition and a strong underprediction of HNCO.

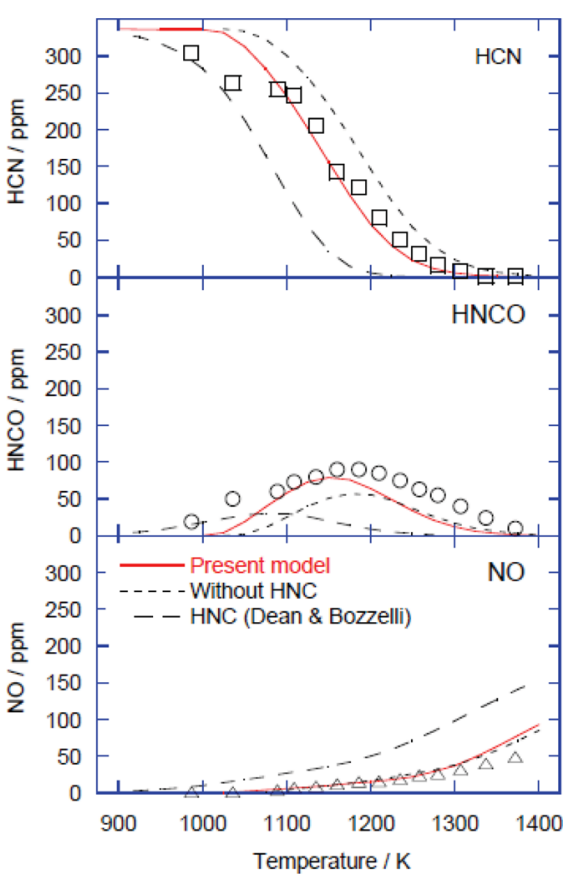

Figure 7. Comparison between experimental data ${ }^{13}$ and modeling predictions for HCN oxidation in a flow reactor. Symbols denote experimental data, while lines denote model predictions. Inlet concentrations: $337 \mathrm{ppm}$ of $\mathrm{HCN}, 2.6 \% \mathrm{O}_{2}, 3.1 \% \mathrm{H}_{2} \mathrm{O}$, and balance $\mathrm{N}_{2}$. The pressure is $1.05 \mathrm{~atm}$, and the residence time at $1200 \mathrm{~K}$ (constant constant mass flow) is $112 \mathrm{~ms}$.

In Figure 8, jet-stirred reactor experiments reported by Dagaut et al. $^{92}$ for the oxidation of $\mathrm{HCN}$ are compared to

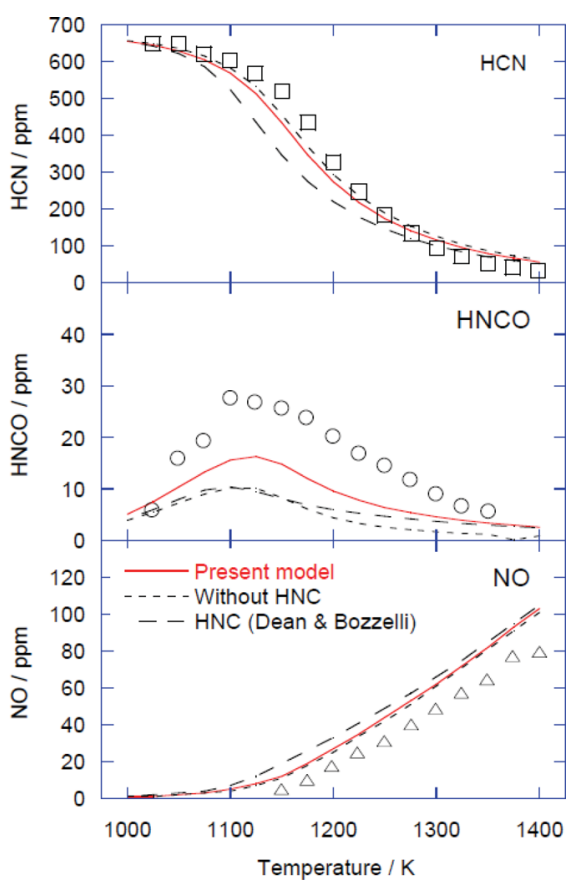

Figure 8. Comparison between experimental data ${ }^{92}$ and modeling predictions for HCN oxidation in a jet-stirred reactor. Symbols denote experimental data, while lines denote model predictions. Inlet concentrations: $670 \mathrm{ppm}$ of $\mathrm{HCN}, 2000 \mathrm{ppm}$ of $\mathrm{O}_{2}, 200 \mathrm{ppm}$ of $\mathrm{H}_{2} \mathrm{O}$, and balance $\mathrm{N}_{2}$. The pressure is $1.0 \mathrm{~atm}$, and the residence time is $120 \mathrm{~ms}$. 
modeling predictions. The modeling predictions agree well with the measured profiles for $\mathrm{HCN}$ and $\mathrm{NO}$, but $\mathrm{HNCO}$ is underpredicted by almost a factor of 2. Exclusion of the HNC subset has only a small impact on $\mathrm{HCN}$ and NO predictions but acts to increase the discrepancy for HNCO. Use of the HNC subset from Dean and Bozzelli leads to a too fast calculated consumption of $\mathrm{HCN}$ and also has an adverse impact on the HNCO prediction.

\section{CONCLUSION}

The chemistry of HNC and its role in combustion nitrogen chemistry have been re-examined. The $\mathrm{HNC}+\mathrm{O}_{2}$ reaction was studied by $a b$ initio methods and shown to have a high barrier. With an updated kinetic subset for the HNC chemistry, including an accurate value of the heat of formation for HNC and improved rate constants for $\mathrm{HNC}+\mathrm{O}_{2}$ and $\mathrm{HNC}+\mathrm{OH}$, it was possible to reconcile modeling issues and provide a satisfactory prediction of a wide range of experimental results on HCN oxidation. In the burned gases of fuel-rich flames, where $\mathrm{HCN}$ and $\mathrm{CN}$ are partially equilibrated, the sequence $\mathrm{HCN} \stackrel{+\mathrm{M}}{\longrightarrow} \mathrm{HNC} \stackrel{+\mathrm{OH}}{\longrightarrow} \mathrm{HNCO}$ is the major consumption path for HCN. Under lean conditions, HNC is shown to be less important than indicated by the early work of Lin and coworkers but acts to accelerate $\mathrm{HCN}$ oxidation and promote the formation of HNCO.

\section{ASSOCIATED CONTENT}

\section{S Supporting Information}

The Supporting Information is available free of charge on the ACS Publications website at DOI: 10.1021/acs.energyfuels.6b02085.

$$
\text { Full model (ASCII) (TXT) }
$$

\section{AUTHOR INFORMATION}

\section{Corresponding Author}

*E-mail: pgl@kt.dtu.dk.

\section{Notes}

The authors declare no competing financial interest.

\section{ACKNOWLEDGMENTS}

The work is part of the Combustion and Harmful Emission Control (CHEC) research program. It was financially supported by the Technical University of Denmark. Paul Marshall thanks the R. A. Welch Foundation (Grant B-1174) for support. Peter Glarborg thanks Drs. Branko Ruscic, Stephen Klippenstein, and James A. Miller for helpful discussions.

\section{REFERENCES}

(1) Miller, J. A.; Bowman, C. T. Prog. Energy Combust. Sci. 1989, 15, 287-338.

(2) Bowman, C. T. Symp. Combust., [Proc.] 1992, 24, 859-878.

(3) Glarborg, P.; Jensen, A. D.; Johnsson, J. E. Prog. Energy Combust. Sci. 2003, 29, 89-113.

(4) Glarborg, P. Proc. Combust. Inst. 2007, 31, 77-98.

(5) Lucassen, A.; Zhang, K.; Warkentin, J.; Moshammer, K.; Glarborg, P.; Marshall, P.; Kohse-Höinghaus, K. Combust. Flame 2012, 159, 2254-2279.

(6) Haynes, B. S.; Iverach, D.; Kirov, N. Y. Symp. Combust., [Proc.] 1975, 15, 1103-1112.

(7) Fenimore, C. P. Combust. Flame 1976, 26, 249-256.

(8) Haynes, B. S. Combust. Flame 1977, 28, 113-121.
(9) Dagaut, P.; Glarborg, P.; Alzueta, M. U. Prog. Energy Combust. Sci. 2008, 34, 1-46.

(10) Lin, M. C.; He, Y.; Melius, C. F. Int. J. Chem. Kinet. 1992, 24, 1103-1107.

(11) Dean, A. M.; Bozzelli, J. W. Combustion chemistry of nitrogen. In Gas Phase Combustion Chemistry; Gardiner, W. C., Ed.; Springer: New York, 2000; Chapter 2, pp 125-341, DOI: 10.1007/978-1-46121310-9 2.

(12) Gimenez-Lopez, J.; Millera, A.; Bilbao, R.; Alzueta, M. U. Combust. Flame 2010, 157, 267-276.

(13) Glarborg, P.; Miller, J. A. Combust. Flame 1994, 99, 475-483.

(14) Lamoureux, N.; Merhubi, H. E.; Pillier, L.; de Persis, S.; Desgroux, P. Combust. Flame 2016, 163, 557-575.

(15) Pearson, P. K.; Schaefer, H. F.; Wahlgren, U. J. Chem. Phys. $1975,62,350-354$.

(16) Vonniessen, W.; Cederbaum, L. S.; Domcke, W.; Diercksen, G. H. F. Mol. Phys. 1976, 32, 1057-1061.

(17) Ishida, K.; Morokuma, K.; Komornicki, A. J. Chem. Phys. 1977, 66, 2153-2156

(18) Dorschner, R.; Kaufmann, G. Inorg. Chim. Acta 1977, 23, 97101.

(19) Gray, S. K.; Miller, W. H.; Yamaguchi, Y.; Schaefer, H. F. J. Chem. Phys. 1980, 73, 2733-2739.

(20) Redmon, L. T.; Purvis, G. D.; Bartlett, R. J. J. Chem. Phys. 1980, 72, 986-991.

(21) Vazquez, G. J.; Gouyet, J. F. Chem. Phys. Lett. 1981, 77, 233238.

(22) Maki, A. G.; Sams, R. L. J. Chem. Phys. 1981, 75, 4178-4182.

(23) Maricq, M. M.; Smith, M. A.; Simpson, C. J. S. M.; Ellison, G. B. J. Chem. Phys. 1981, 74, 6154-6170.

(24) Pau, C. F.; Hehre, W. J. J. Phys. Chem. 1982, 86, 321-322.

(25) Peric, M.; Mladenovic, M.; Peyerimhoff, S. D.; Buenker, R. J. Chem. Phys. 1983, 82, 317-336.

(26) Glidewell, C.; Thomson, C. J. Comput. Chem. 1984, 5, 1-10.

(27) Peric, M.; Mladenovic, M.; Peyerimhoff, S. D.; Buenker, R. J. Chem. Phys. 1984, 86, 85-103.

(28) Waite, B. A. J. Phys. Chem. 1984, 88, 5076-5083.

(29) Bacic, Z.; Gerber, R. B.; Ratner, M. A. J. Phys. Chem. 1986, 90, $3606-3612$.

(30) Smith, R. S.; Shirts, R. B.; Patterson, C. W. J. Chem. Phys. 1987, $86,4452-4460$.

(31) Szalay, V. J. Chem. Phys. 1990, 92, 3633-3644.

(32) Lee, T. J.; Rendell, A. P. Chem. Phys. Lett. 1991, 177, 491-497.

(33) Lan, B. L.; Bowman, J. M. J. Phys. Chem. 1993, 97, 1253512540 .

(34) Bowman, J. M.; Gazdy, B.; Bentley, J. A.; Lee, T. J.; Dateo, C. E. J. Chem. Phys. 1993, 99, 308-323.

(35) Gazdy, B.; Musaev, D. G.; Bowman, J. M.; Morokuma, K. Chem. Phys. Lett. 1995, 237, 27-32.

(36) Zhao, M. S. Chin. J. Chem. 1995, 13, 141-149.

(37) Talbi, D.; Ellinger, Y.; Herbst, E. Astron. Astrophys. 1996, 314, 688-692.

(38) Talbi, D.; Ellinger, Y. Chem. Phys. Lett. 1996, 263, 385-392.

(39) Rao, V. S.; Vijay, A.; Chandra, A. K. Can. J. Chem. 1996, 74, $1072-1077$.

(40) Jursic, B. S. J. Chem. Soc., Faraday Trans. 1997, 93, 2355-2359. (41) Bowman, J. M.; Gazdy, B. J. Phys. Chem. A 1997, 101, 63846388.

(42) Contreras, R.; Safont, V. S.; Pérez, P.; Andrés, J.; Moliner, V.; Tapia, O. J. Mol. Struct.: THEOCHEM 1998, 426, 277-288.

(43) Kumeda, Y.; Minami, Y.; Takano, K.; Taketsugu, T.; Hirano, T. J. Mol. Struct.: THEOCHEM 1999, 458, 285-291.

(44) Christoffel, K. M.; Bowman, J. M. J. Chem. Phys. 2000, 112, 4496-4505.

(45) Wenthold, P. G. J. Phys. Chem. A 2000, 104, 5612-5616.

(46) van Mourik, T.; Harris, G. J.; Polyansky, O. L.; Tennyson, J.; Csaszar, A. G.; Knowles, P. J. J. Chem. Phys. 2001, 115, 3706-3718.

(47) Barber, R. J.; Harris, G. J.; Tennyson, J. J. Chem. Phys. 2002, 117, 11239-11243. 
(48) Liao, X. L.; Wu, W.; Mo, Y. R; Zhang, Q. N. Sci. China, Ser. B: Chem. 2003, 46, 361-370.

(49) Isaacson, A. D. J. Phys. Chem. A 2006, 110, 379-388.

(50) Harris, G. J.; Tennyson, J.; Kaminsky, B. M.; Pavlenko, Y. V.; Jones, H. R. A. Mon. Not. R. Astron. Soc. 2006, 367, 400-406.

(51) Mellau, G. C.; Winnewisser, B. P.; Winnewisser, M. J. Mol. Spectrosc. 2008, 249, 23-42.

(52) DePrince, A. E., III; Mazziotti, D. A. J. Phys. Chem. B 2008, 112, $16158-16162$.

(53) Quapp, W.; Zech, A. J. Comput. Chem. 2010, 31, 573-585.

(54) Mellau, G. C. J. Chem. Phys. 2010, 133, 164303.

(55) Mellau, G. C. J. Mol. Spectrosc. 2010, 264, 2-9.

(56) Mellau, G. C. J. Chem. Phys. 2011, 134, 234303.

(57) Mellau, G. C. J. Mol. Spectrosc. 2011, 269, 77-85.

(58) Mellau, G. C. J. Chem. Phys. 2011, 134, 194302.

(59) Mellau, G. C. J. Mol. Spectrosc. 2011, 269, 12-20.

(60) Hebrard, E.; Dobrijevic, M.; Loison, J. C.; Bergeat, A.; Hickson,

K. M. Astron. Astrophys. 2012, 541, A21.

(61) Barber, R. J.; Strange, J. K.; Hill, C.; Polyansky, O. L.; Mellau, G. C.; Yurchenko, S. N.; Tennyson, J. Mon. Not. R. Astron. Soc. 2014, 437, $1828-1835$.

(62) Vichietti, R. M.; Haiduke, R. L. A. Mon. Not. R. Astron. Soc. 2014, 437, 2351-2360.

(63) Loison, J. C.; Wakelam, V.; Hickson, K. M. Mon. Not. R. Astron. Soc. 2014, 443, 398-410.

(64) Gutiérrez-Oliva, J. S.; Díaz, S.; Toro-Labbé, A.; Lane, P.; Murray, J. S.; Politzer, P. Mol. Phys. 2014, 112, 349-354.

(65) Gutiérrez-Oliva, S.; Díaz, S.; Toro-Labbé, A.; Lane, P.; Murray, J. S.; Politzer, P. Mol. Phys. 2014, 112, 349-354.

(66) Baraban, J. H.; Changala, P. B.; Mellau, G. C.; Stanton, J. F.; Merer, A. J.; Field, R. W. Science 2015, 350, 1338-1342.

(67) Nguyen, T. L.; Baraban, J. H.; Ruscic, B.; Stanton, J. F. J. Phys. Chem. A 2015, 119, 10929-10934.

(68) Hashemi, H.; Christensen, J. M.; Gersen, S.; Glarborg, P. Proc. Combust. Inst. 2015, 35, 553-560.

(69) Rasmussen, C. L.; Rasmussen, A. E.; Glarborg, P. Combust. Flame 2008, 154, 529-545.

(70) Tian, Z.; Li, Y.; Zhang, L.; Glarborg, P.; Qi, F. Combust. Flame 2009, 156, 1413-1426.

(71) Mendiara, T.; Glarborg, P. Combust. Flame 2009, 156, 19371949.

(72) Mendiara, T.; Glarborg, P. Energy Fuels 2009, 23, 3565-3572.

(73) Klippenstein, S. J.; Harding, L. B.; Glarborg, P.; Miller, J. A. Combust. Flame 2011, 158, 774-789.

(74) Abian, M.; Alzueta, M. U.; Glarborg, P. Int. J. Chem. Kinet. 2015, $47,518-532$.

(75) Song, Y.; Hashemi, H.; Christensen, J. M.; Zou, C.; Marshall, P.; Glarborg, P. Fuel 2016, 181, 358-365.

(76) Talbi, D.; Ellinger, Y. Chem. Phys. Lett. 1998, 288, 155-164.

(77) Hansel, A.; Scheiring, C.; Glantschnig, M.; Lindinger, W.; Ferguson, E. E. J. Chem. Phys. 1998, 109, 1748-1750.

(78) Goos, E.; Burcat, A.; Ruscic, B. Ideal Gas Thermochemical Database with Updates from Active Thermochemical Tables; ftp://ftp. technion.ac.il/pub/supported/aetdd/thermodynamics mirrored at http://garfield.chem.elte.hu/burcat/burcat.html.

(79) Ruscic, B.; Pinzon, R. E.; Morton, M. L.; von Laszevski, G.; Bittner, S.; Nijsure, S. G.; Amin, K. A.; Minkoff, M.; Wagner, A. F. J. Phys. Chem. A 2004, 108, 9979-9997.

(80) Ruscic, B.; Pinzon, R. E.; von Laszewski, G.; Kodeboyina, D.; Burcat, A.; Leahy, D.; Montoy, D.; Wagner, A. F. J. Phys.: Conf. Ser. 2005, 16, 561-570.

(81) Tsang, W.; Herron, J. T. J. Phys. Chem. Ref. Data 1991, 20, 609663.

(82) Baulch, D. L.; Bowman, C. T.; Cobos, C. J.; Cox, R. A.; Just, T.; Kerr, J. A.; Pilling, M. J.; Stocker, D.; Troe, J.; Tsang, W.; Walker, R. W.; Warnatz, J. J. Phys. Chem. Ref. Data 2005, 34, 757-1397.

(83) Wooldridge, S. T.; Hanson, R. K.; Bowman, C. T. Int. J. Chem. Kinet. 1995, 27, 1075-1087.
(84) Miller, J. A.; Melius, C. F. Symp. Combust., [Proc.] 1988, 21, 919-927.

(85) Sumathi, R.; Nguyen, M. T. J. Phys. Chem. A 1998, 102, 80138020.

(86) Bunkan, A. J. C.; Tang, Y.; Sellevag, S. R.; Nielsen, C. J. J. Phys. Chem. A 2014, 118, 5279-5288.

(87) Jiang, B.; Guo, H. J. Chem. Phys. 2013, 139, 224310.

(88) Montgomery, J. A.; Frisch, M. J.; Ochterski, J. W.; Petersson, G. A. J. Chem. Phys. 1999, 110, 2822-2827.

(89) Frisch, M. J.; et al. Gaussian 09; Gaussian, Inc.: Wallingford, CT, 2000.

(90) Jacobs, A.; Wahl, M.; Weller, R.; Wolfrum, J. Chem. Phys. Lett. 1988, 144, 203-207.

(91) Higashihara, T.; Saito, K.; Murakami, I. J. Phys. Chem. 1983, 87, $3707-3712$.

(92) Dagaut, P.; Lecomte, F.; Chevailler, S.; Cathonnet, M. Combust. Sci. Technol. 2000, 155, 105-127. 